\title{
Functional diversity of habitat formers declines scale-dependently across an environmental stress gradient
}

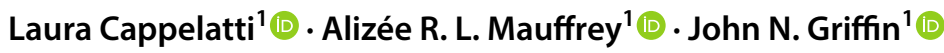

Received: 15 December 2019 / Accepted: 27 August 2020 / Published online: 7 September 2020

(c) The Author(s) 2020

\begin{abstract}
Marine habitat formers such as seaweeds and corals are lynchpins of coastal ecosystems, but their functional diversity and how it varies with scale and context remains poorly studied. Here, we investigate the functional diversity of seaweed assemblages across the rocky intertidal stress gradient at large (zones) and small (quadrat) scales. We quantified complementary metrics of emergent group richness, functional richness (functional space occupied) and functional dispersion (trait complementarity of dominant species). With increasing shore height, under species loss and turnover, responses of functional diversity were scale- and metric-dependent. At the large scale, functional richness contracted while-notwithstanding a decline in redundancy-emergent group richness and functional dispersion were both invariant. At the small scale, all measures declined, with the strongest responses evident for functional and emergent group richness. Comparisons of observed versus expected values based on null models revealed that functional richness and dispersion were greater than expected in the low shore but converged with expected values higher on the shore. These results show that functional diversity of assemblages of marine habitat formers can be especially responsive to environmental stress gradients at small scales and for richness measures. Furthermore, niche-based processes at the small—neighbourhood—scale can favour co-occurrence of functionally distinctive species under low, but not high, stress, magnifying differences in functional diversity across environmental gradients. As assemblages of marine habitat formers face accelerating environmental change, further studies examining multiple aspects of functional diversity are needed to elucidate patterns, processes, and ecosystem consequences of community (dis-)assembly across diverse groups.
\end{abstract}

Keywords Emersion gradient $\cdot$ Seaweed $\cdot$ Functional traits $\cdot$ Emergent groups $\cdot$ Assembly patterns

\section{Introduction}

Biodiversity is increasingly recognised as multidimensional, including taxonomic, phylogenetic, and functional components (Cadotte et al. 2009; Devictor et al. 2010; Stevens and Gavilanez 2015). Functional traits such as body size, mouthpart- or leaf- morphology determine an organism's capacity to process resources and how it experiences

Communicated by Daniel C Reed .

Electronic supplementary material The online version of this article (https://doi.org/10.1007/s00442-020-04746-1) contains supplementary material, which is available to authorized users.

Laura Cappelatti

lauracappelatti@gmail.com

1 Biosciences Department, Swansea University, Wallace Building, Swansea SA2 8PP, Wales, UK and interacts with its environment. The diversity of such traits-functional diversity - captures variation in the ecological roles of species (Tilman 2001; Violle et al. 2007; Díaz et al. 2020). Although ecologists have traditionally focused on taxonomy-based metrics of biodiversity, incorporating functional diversity allows a more complete view of how communities respond to environmental gradients and human pressures (Mouillot et al. 2013; Teixidó et al. 2018; Sol et al. 2020; Muguerza et al. 2020), elucidates the relationships between biodiversity and ecosystem functioning (e.g. Griffin et al. 2009; Lefcheck and Duffy 2015), and reveals the operation of niche-based processes during community assembly (Mcgill et al. 2006). Functional diversity approaches have been widely tested and applied in terrestrial ecosystems structured by primary producers and habitat formers such as trees, grasses, and climbing plants (Roderick et al. 2000; Mokany and Ash 2008; Seger et al. 2017). There is now growing interest in applying functional diversity 
approaches to assemblages of habitat formers in marine and coastal ecosystems as they rapidly reorganise under global change (Blowes et al. 2019; Antão et al. 2020).

Habitat-forming organisms such as corals, seagrasses, and seaweeds form diverse assemblages and support associated biodiversity and ecosystem functioning in many coastal environments worldwide (Stachowicz et al. 2007; Thomsen et al. 2010; Teagle et al. 2017; Vergés et al. 2019). In temperate nearshore systems, macroalgae (seaweeds) often dominate standing biomass and contribute to services from carbon sequestration to coastal defence and fisheries support (Smale et al. 2013). Global changes including ocean warming and acidification, invasive non-native species and coastal urbanisation are driving marked shifts in seaweed assemblages (Wernberg et al. 2011; Harley et al. 2012). Functional approaches to seaweed assemblages predominantly involve grouping species based on position in the canopy (e.g. Tait et al. 2014) or general morphology (e.g. Steneck and Dethier 1994). Yet the functionality of species and assemblages is determined by multiple, often continuous, traits, challenging coarse a priori grouping (Chapin et al. 1996; Fong and Fong 2014; Mauffrey et al. 2020a). Here, we use the rocky intertidal as a test case for applying a suite of continuous traits to seaweeds to understand patterns of functional diversity across environmental gradients.

Multiple, complementary, metrics are required to describe how functional diversity changes along gradients of disturbance or stress (Villéger et al. 2008; Mouillot et al. 2013). Functional diversity can be quantitatively defined as the distribution of species in a functional space where the axes represent combinations of traits (Rosenfeld 2002; Mason et al. 2005; Villéger et al. 2008). Metrics used to describe functional diversity include functional richness- the total extent of species in trait space- and functional dispersionthe distinctness of dominant species (Laliberté and Legendre 2010). Functional richness and dispersion indicate the potential for species complementarity, respectively emphasising differences between extreme and abundant species (Mason et al. 2005; Kuebbing et al. 2018). Although declines in species richness along environmental gradients are expected to erode redundancy and particularly affect functional richness, these changes can be buffered in systems with high redundancy (Micheli and Halpern 2005; but see Mouillot et al. 2014). Contrarily, strong environmental constraints on the viable traits (environmental filtering) can drive greaterthan-expected declines in functional richness (Mouillot et al. 2013; Valdivia et al. 2017; Teixidó et al. 2018) and may reduce the dispersion of dominant species (Schellenberger Costa et al. 2017). Investigating changes in multiple facets of functional diversity across environmental gradients can, therefore, add to the traditional taxonomic focus and provide a complementary lens to understand community structure and potential consequences for ecosystem functioning (Díaz and Cabido 2001; Zhang et al. 2012).

The rocky intertidal has long served as a proving ground for ecological ideas due to its accessible marine communities and provides a model system to examine functional diversity of seaweeds along an environmental stress gradient. The intertidal rocky shore is characterised by a vertical pattern of community turnover (or 'zonation') and decreasing species richness. These community changes are driven by an interplay between biotic interactions and species' tolerances to tidal emersion period and associated stressors of desiccation, temperature extremes and nutrient scarcity (e.g. Schonbeck and Norton 1979; Underwood and Jernakoff 1984; Scrosati and Heaven 2007). The intertidal stress gradient can be mitigated by rock pools which create habitat heterogeneity on beds of emergent rock and commonly host different suites of less desiccation-tolerant species (Araújo et al. 2006; Firth et al. 2014). The rocky shore and attendant community gradients remain a classic research and teaching system in ecology and are prominent in contemporary ecological textbooks (Begon et al. 1996; Singer 2016). Zonation patterns in seaweed communities have been studied in rocky shores in several parts of the world: from the North Atlantic (Lubchenco 1980; Dring and Brown 1982) to high latitudes of Alaska and the Magellanic region (Ingólfsson 2005). However, beyond studies of the traits of dominant species (Gómez and Huovinen 2011; Cappelatti et al. 2019), the corresponding responses of functional diversity in these assemblages remain poorly appreciated.

Here, we revisit the classical pattern of intertidal seaweed zonation from a functional perspective. With information on community composition and species' traits across four rocky shores in Wales (UK), we investigated the functional structure of seaweed assemblages along the emersion gradient (shore height). First, we hypothesised that the increasing stress towards the upper intertidal would act as an environmental filter, constraining viable trait values and resulting in a disproportionate loss of functional diversity relative to species loss. Second, we hypothesised that a turnover in species composition would lead to a functional turnover in communities, as trait values reflect different adaptations to the upper shore environment. To address these hypotheses, we examined changes in diversity across the shore height gradient at the scale of entire zones (total species lists) and local communities (replicate quadrats). We further investigated the role of rock pools in modifying diversity gradients via habitat heterogeneity and explored functional redundancy across zones by assigning species to clusters in trait space (i.e. emergent groups). 


\section{Materials and methods}

\section{Study sites and survey}

We studied macroalgal communities along the intertidal gradient across four rocky shores in the Gower peninsula, south Wales (UK). The carboniferous limestone shores span ca. $25 \mathrm{~km}$, and have a tidal variation of approximately $10.4 \mathrm{~m}$ : Oxwich (sheltered; $51.55 \mathrm{~N}, 4.15 \mathrm{~W}$ ), Bracelet Bay (semiexposed; $51.57 \mathrm{~N}, 3.98 \mathrm{~W}$ ), Overton (exposed; $51.53 \mathrm{~N}$, $4.21 \mathrm{~W}$ ) and Rhossili (exposed; $51.56 \mathrm{~N}, 4.32 \mathrm{~W}$ ).

Surveys were conducted during the summer of 2018, by identifying and quantifying all living macroalgal species within $1 \times 1 \mathrm{~m}$ quadrats, placed $10 \mathrm{~m}$ apart along four transects. Each transect crossed the whole intertidal from the kelp zone in the lower shore to the end of seaweed distribution in the upper shore. We sampled the low shore at low tides only during spring tides $(0-0.5 \mathrm{~m}$ above chart datum). Cover was estimated within quadrats with the help of strings which divided the quadrat into 25 sub-units (each unit $=4 \%$ cover). Individuals were thoroughly manipulated to ensure inclusion of small, understory seaweeds, therefore, the multi-layered communities could surpass $100 \%$ cover.
To address the intertidal emersion gradient, we used commonly defined zones of the low, middle, and upper shore (Fig. 1). In agreement with previous studies (Stephenson and Stephenson 1949; Ballantine 1961; Johnson et al. 1998; Chappuis et al. 2014), these zones were defined by their relative position in the intertidal combined with the identity of dominant Phaeophytes (fucoids and kelp). Specifically, zones were delimited where the following species alone or together comprised in excess of $80 \%$ of the total macroalgal cover: low shore-Laminaria digitata and Fucus serratus; mid-shore-Ascophyllum nodosum and $F$. vesiculosus; upper shore-Pelvetia canaliculata and $F$. spiralis. To obtain a clearer distinction between zones, we excluded quadrats falling in the transition between zones as defined above; accordingly, zones were separated by at least $20 \mathrm{~m}$. Although zone serves as an indicator of shore height, and thus emersion period, the exact position of these zones along shore height gradients depends on additional factors such as wave exposure and disturbance history (Ballantine 1961). These three main zones are thus conceptualised as 'community types' positioned sequentially with respect to shore height rather than communities occurring at precise shore heights. In our study, the characteristic fucoids or kelps in each zone
Fig. 1 Conceptual illustration of study scales and description of diversity metrics. Flags next to each metric indicate at which scale they were measured: in green, small scale (quadrat) and in orange, large scale (zone). Triangles indicate cases where we also compared observed to null values

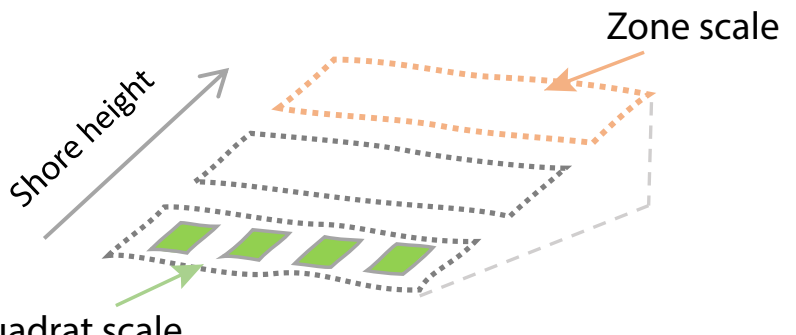

Quadrat scale

\begin{tabular}{|c|c|}
\hline a-diversity & $\beta$-diversity \\
\hline Species richness & Species nestedness \\
\hline Number of species & $\begin{array}{l}\text { Communities with fewer species } \\
\text { are subsets of communities }\end{array}$ \\
\hline Emergent group richness & with more species \\
\hline Number of groups & Functional nestedness \\
\hline $\begin{array}{l}\text { Functional richness } \\
\text { Proportion of the maximum }\end{array}$ & $\begin{array}{l}\text { Functional space of some } \\
\text { communities are subsets of other } \\
\text { communities }\end{array}$ \\
\hline & Species turnover \\
\hline $\begin{array}{l}\text { Functional dispersion } \\
\text { Mean distance of species }\end{array}$ & $\begin{array}{l}\text { Replacement of species between } \\
\text { communities }\end{array}$ \\
\hline to the centroid of trait space & Functional turnover \\
\hline$\square$ scale $\quad \Delta$ null model & space between communities \\
\hline
\end{tabular}


comprise a minority of the assemblage (low shore: $5 \%$; mid-shore: $6 \%$; upper shore: $11 \%$ ) and our findings are robust to exclusion of these species (Appendix 1, ESM). Details on the sampling effort across zones are in Appendix 2, ESM.

\section{Habitats}

We distinguish between two simple habitat types on the rocky shore: emergent rock and rock pool. During the survey, we recorded the percentage cover of these two habitat types. Preliminary analyses revealed that the distribution of rock pool cover was highly uneven, with half of the quadrats having zero cover. Furthermore, the relationship between rock pool cover on seaweed species richness was complex and mostly realised within the first 5\% of cover. Accordingly, for simplicity, we treat rock pools as a binary presence $(\geq 5 \%$ cover) or absence $(<5 \%)$ variable. Quadrats that landed at least partially on gullies or deep rock pools ( $>50 \mathrm{~cm}$ depth) were not considered, since the projected area would be much larger than the other quadrats.

After sampling all shores, we randomly selected a subset of quadrats to obtain an equal representation of combinations of shore zone (low, middle, and upper shore) and habitat (presence/absence of rock pools). The final analysed community data comprised 84 quadrats, 14 for each zone and habitat category combination. Of the selected quadrats, 15 were from Bracelet Bay, and 22, 23, and 24 from the remaining sites.

\section{Trait data}

Traits were obtained from a database in development since 2016 (see Mauffrey et al. 2020b). For the creation of this trait database, we conducted frequent summer sampling trips predominantly in south Wales; all but two of the species in this study were sampled for trait screening from the same sites as the survey data used here. We collected a minimum of 3 individuals per species (mean and mode $=6$, $\max =45$ ). This wide range in replicates is due to the varying abundance of species, and to our efforts to sample abundant species at different sites to capture their intraspecific variation (Cappelatti et al. 2019). To obtain comparable traits, we restricted our study to erect macroalgae only (i.e. not encrusting forms).

The traits we chose are "functional markers" (sensu Garnier et al. 2004) and thus are proxies for physiological or physical functions. We summarise the traits in Table 1 and describe methods for their collection as well as ecological relevance in Appendix 3 (ESM). Prior to analyses, all traits were log-transformed and scaled to zero mean and unit variance, to approach normal distributions and have the same range of variation. Traits were always measured at the species level; however, some species require laboratory identification, so they were only identified at the genus level. In the case of Ulva, this genus was further divided into two groups related to obvious phenotypic differences. For the artificial taxa "green sheet", we used trait averages from $U$. linza and $U$. lactuca; for "green tubular" we used trait averages from $U$. intestinalis and $U$. compressa.

\section{Trait space of species}

Species' functional trait differences were characterised based on a Gower distance matrix, at the whole study scale. Traits were weighted to ensure that all three aspects of functionality considered here (photosynthesis, physical structure, complexity) were equally represented (Table 1). To visualise species' functional diversity as captured in the Gower distance matrix, we used principal coordinate analysis ( $\mathrm{PCoA}$ ) and displayed the first two axes, which explained $61 \%$ of inertia (Fig. 2; see Appendix 3, ESM, for further details of the quality of functional space representation).

To examine species' contributions to functional diversity and redundancy across zones, we also addressed species' occupancy of parts of the trait space via emergent groups. Because emergent groups are based on measured traits, they should be a more accurate representation of species' differences than the traditional functional groups (Mauffrey et al. 2020a). In our study communities, emergent groups allowed us to observe redundancy (species within groups share similar trait values) and how parts of the trait space (as occupied by different groups) change across zones. Species were grouped based on the Gower distance matrix, using the $k$-medoids clustering method (Reynolds et al. 2006) applied with pam in package cluster (Maechler et al. 2019). We tested increasing numbers of groups and selected the highest number of groups (i.e. 6) where all pairwise contrasts using PERMANOVA were significant at $\alpha=0.05$ (Hervé 2020; Mauffrey et al. 2020a).

\section{Diversity metrics}

We calculated species and functional diversity metrics at both the large (zone) and small (quadrat) scales (Fig. 1). The larger-scale includes all quadrats within a zone across the four study sites and provides the most complete estimate of the species occupying the specific zone in the area/region. This scale of diversity includes large-scale heterogeneity across sites and represents species that may contribute to ecosystem functionality over larger spatial and temporal scales (Isbell et al. 2017). The smaller scale of the $1 \times 1 \mathrm{~m}$ quadrat (the local or "neighbourhood" scale) represents the scale at which direct biotic interactions occur between seaweeds (e.g. Edwards and Connell 2012). Seaweeds respond 


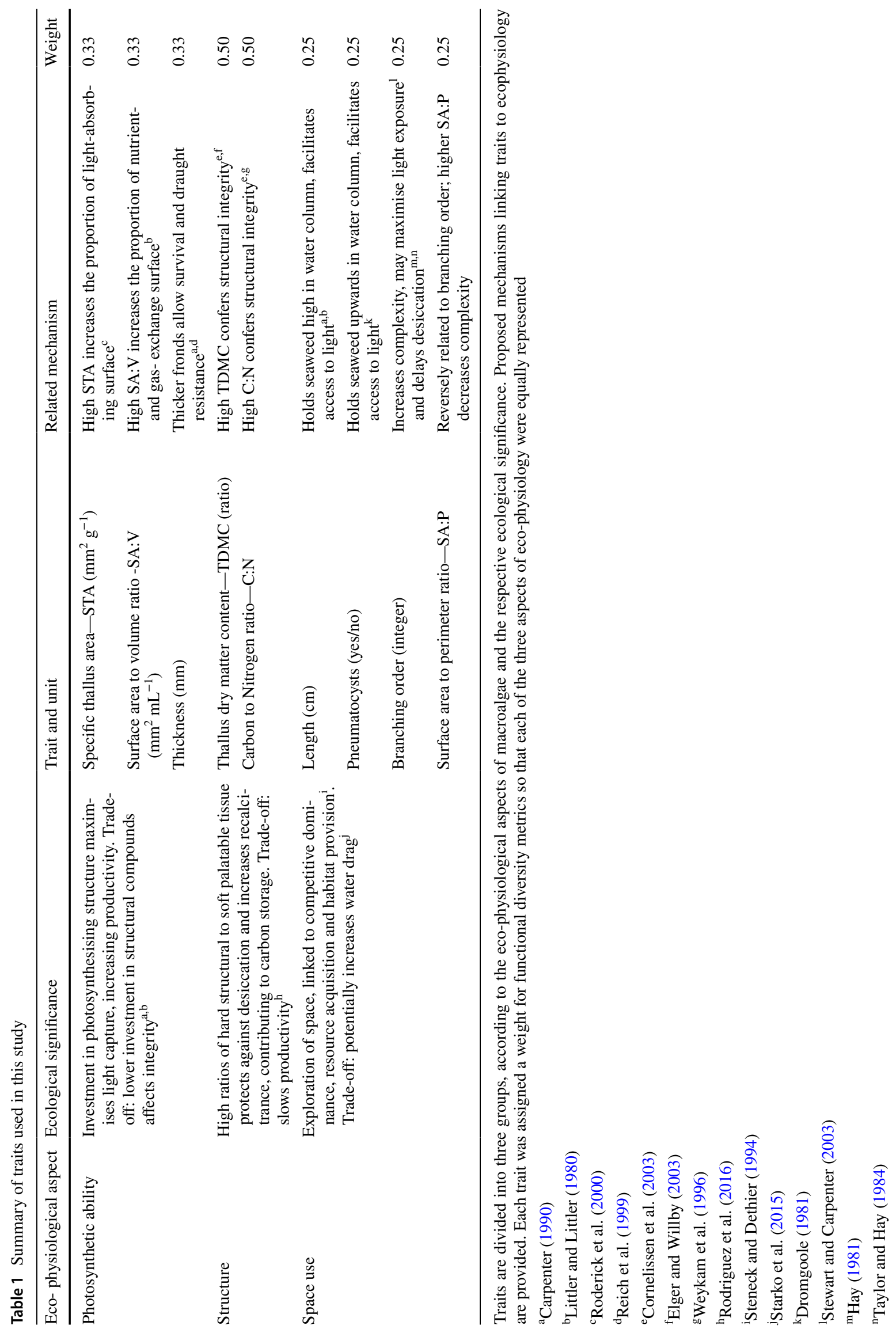


Fig. 2 Principal Coordinates of study species based on 9 traits. Each point represents a species $(n=50)$ and is coloured by the emergent group. Emergent groups (EGs) were created from a trait-based Gower distance and, therefore, may not be fully represented in this two-dimensional plot. Density plots show the distribution of emergent groups along each PCo axis. Arrows summarise correlations between traits and axes

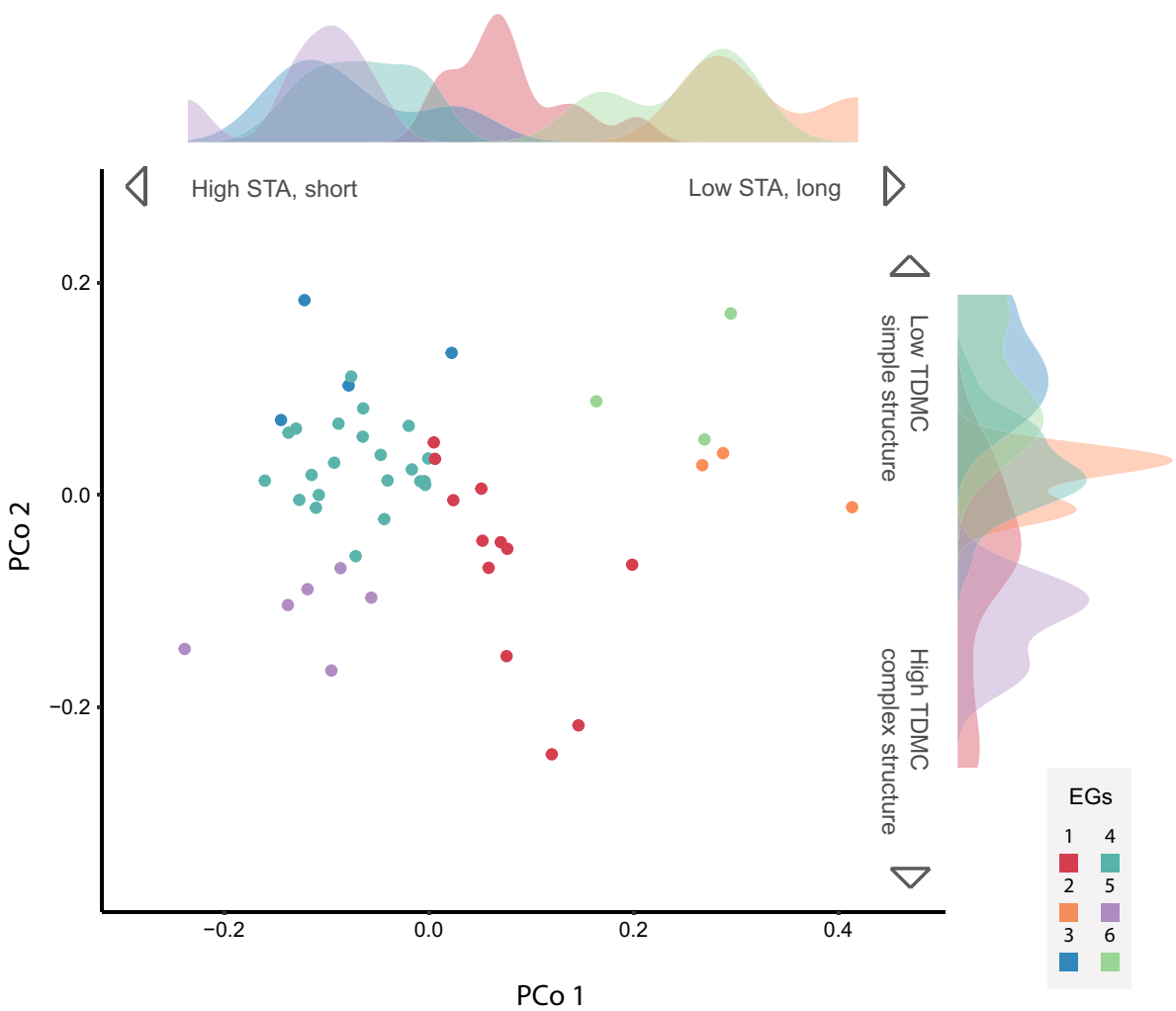

to the stresses associated with shore height at both scales, but community composition also varies at the quadrat scale due to differences in local factors such as the presence of rock pools.

We calculated four complementary $\alpha$-diversity metrics: species richness, emergent group richness, functional richness, and functional dispersion (Fig. 1). Species and emergent group richness are simply the total number of species or emergent groups present at a focal scale. While species richness is a standard metric of biodiversity in rocky shore assemblages (e.g. Scrosati et al. 2011) and treats all species equally, emergent group richness is based on species' relative positions in trait space and only declines when entire regions of trait space (emergent groups) have been vacated. Functional richness is the size of the functional space filled by the community, based on the convex hull delimited by the most extreme points in functional space (Cornwell et al. 2006; Villéger et al. 2008). We scaled functional richness to a hypothetical community with all species in the study pool, to benchmark values relative to the potential maximum. Functional dispersion is the mean abundance-weighted distance in multidimensional space of individual species to their overall centroid, thus measuring species' distribution in trait space (Laliberté and Legendre 2010). To calculate functional richness and dispersion, we selected PCoA axes from the Gower distance matrix among communities (details on the PCoA are in Appendix 3, ESM). As the above-described metrics quantify diversity for individual communities, they are measures of $\alpha$-diversity. All $\alpha$-diversity indices were calculated using function $d b F D$ on package $F D$ (Laliberté and Legendre 2010).

Patterns of $\beta$-diversity reveal underlying changes in community structure along environmental gradients (Legendre 2014). While taxonomic $\beta$-diversity captures the changes in the identities of the species, functional $\beta$-diversity captures changes in the locations of species in trait space. To examine $\beta$-diversity across zones, we used the Sorensen index, which measures the ratio of shared species (or overlapping volume of convex hull) among assemblages to the mean number of species (or mean convex hull volume) occurring in a single assemblage (Gotelli and Chao 2013). The returned index is a measure of the multiple site dissimilarity among communities (Baselga 2010). At both species and functional levels, $\beta$-diversity was partitioned between nestedness and turnover components (Fig. 1). These indices were calculated with functions beta.multi (species incidences) and functional.beta.multi (based on the PCoA) in package Betapart (Baselga and Orme 2012).

\section{Statistical analyses}

To investigate if the observed functional diversity metrics of local_small scale_communities were lower or higher than expected based on the number of species within a 
community, we used a null model approach. Null communities (999 in each case) were constructed by shuffling species' position on the trait matrix, thus holding constant the overall functional structure of seaweeds and species richness within each observed community (quadrat), while randomizing the identities of species in each null community (Swenson 2014). We then calculated the standardized effect sizes (SES) of functional richness and functional dispersion, which compares observed to null values (Cadotte and Tucker 2017). For each focal aspect of functional diversity (richness, divergence) and each community $(n=84)$ a single SES value was generated. We used one-sample $t$ tests (or Wilcoxon rank tests, when data distribution was not normal) to compare observed SES values against null SES values.

We used linear models to investigate the additive and interacting effect of shore height (zone) and habitat heterogeneity (presence/absence of rock pool) on species and functional $\alpha$-diversity metrics, and on SES values. We also examined the observed $\alpha$-diversity metrics across sites and found no significant differences in their means; the site was then dropped from the analysis as our focus was on general effects of zone (Appendix 4, ESM).

\section{Results}

\section{Species distribution in the trait space}

Fifty taxa (referred to as species hereafter) were found in the survey: 43 identified at the species level, and seven at the genus level (including the two artificial groups of Ulva). The majority ( $n=33)$ were red algae (phylum Rhodophyta), followed by brown algae ( $n=10$, class Phaeophyceae) and green algae ( $n=7$, phylum Chlorophyta).

The first PCo axis was most strongly related to traits linked to photosynthesis: species with higher PCo 1 values tended to display reduced specific thallus area (STA), reduced surface area to volume ratio $(\mathrm{SA}: \mathrm{V})$ and have thicker thalli (Fig. 2; Table 1). The second axis mainly related to traits representing space use and structure: species with higher PCo 2 values tended to have lower thallus dry matter content (TDMC) and branching order, and higher surface area to perimeter ratio (SA:P). Generally, PCo 1 translates into a trade-off between resource acquisition and conservation (i.e. an "economic" trade-off) and PCo 2 into a complexity / structural gradient. All trait-axis and trait-trait correlations are shown in Appendix 3, ESM. Overall, species were distributed unevenly across the functional space and, therefore, emergent groups had varying numbers of species (from 3 to 22, Figs. 2 and 4). The large richness observed within groups 1 and 4 shows they hold a high degree of redundancy.

\section{Large scale (zone level) diversity patterns}

With increasing shore height, the number of species in each zone declined (Fig. 3a). Changes in the taxonomic composition between zones ( $\beta$-diversity) were divided relatively evenly between nestedness and turnover, regardless of rock pool presence or absence (Fig. 3b). How this taxonomic loss and turnover translated into changes at the functional level depended on the metric. Functional richness peaked in the mid-shore, despite a continuous decline in species richness (Fig. 3c). Meanwhile, functional dispersion did not vary strongly across-shore levels, notwithstanding a slight increase towards higher zones (Fig. 3c). In addition to changes in the size of the functional space, there were also subtle changes in the relative location of the space, i.e. functional $\beta$-diversity (Fig. 3d-e). Unlike at the taxonomic level, these changes were dominated by nestedness rather than turnover (Fig. 3d-f). Indeed, the only observable functional turnover is with the expansion driven by Ascophyllum nodosum in the mid shore (Fig. 3e), while the rest of the changes are clearly via loss of parts of the trait space, especially in the absence of rock pools (Fig. 3f). Despite losses in functional richness, the presence of all emergent groups across zones illustrates the persistence of the overall 'framework' of functional space (Fig. 4a). A further look into emergent group richness between zones indicates that species loss was stronger within some groups than others (Fig. 4b), thus unevenly eroding functional redundancy. Overall, across zones, taxonomic diversity and composition changed more strongly than their functional counterparts.

\section{Small scale (quadrat level) diversity patterns}

Contrary to the zone scale, all $\alpha$-diversity metrics decreased towards the higher shore at the small-scale (Table 2; Fig. 5a-d). Overall, the negative effect of height on diversity was stronger for species and functional richness than for emergent group richness and functional dispersion. Changes in local communities across zones were not constant: while species richness continuously decreased (Fig. 5a), the functional metrics only changed from middle to upper shore (Fig. 5b-d). Emergent group richness was strongly related to species richness $\left(\mathrm{R}^{2}=0.83\right.$; see Appendix 5, ESM, for relationships between functional diversity metrics and species richness). Moreover, the presence of rock pools had an additive effect on all diversity metrics (Table 2). Generally, at the small scale, we observed further declines in functional diversity metrics with height, which were not evident at the large scale.

The standardised effect size (SES; comparing observed to null communities) showed different patterns for functional richness and dispersion (Table 2; Fig. 5e-f). Greater-thanexpected values were observed for functional richness at 


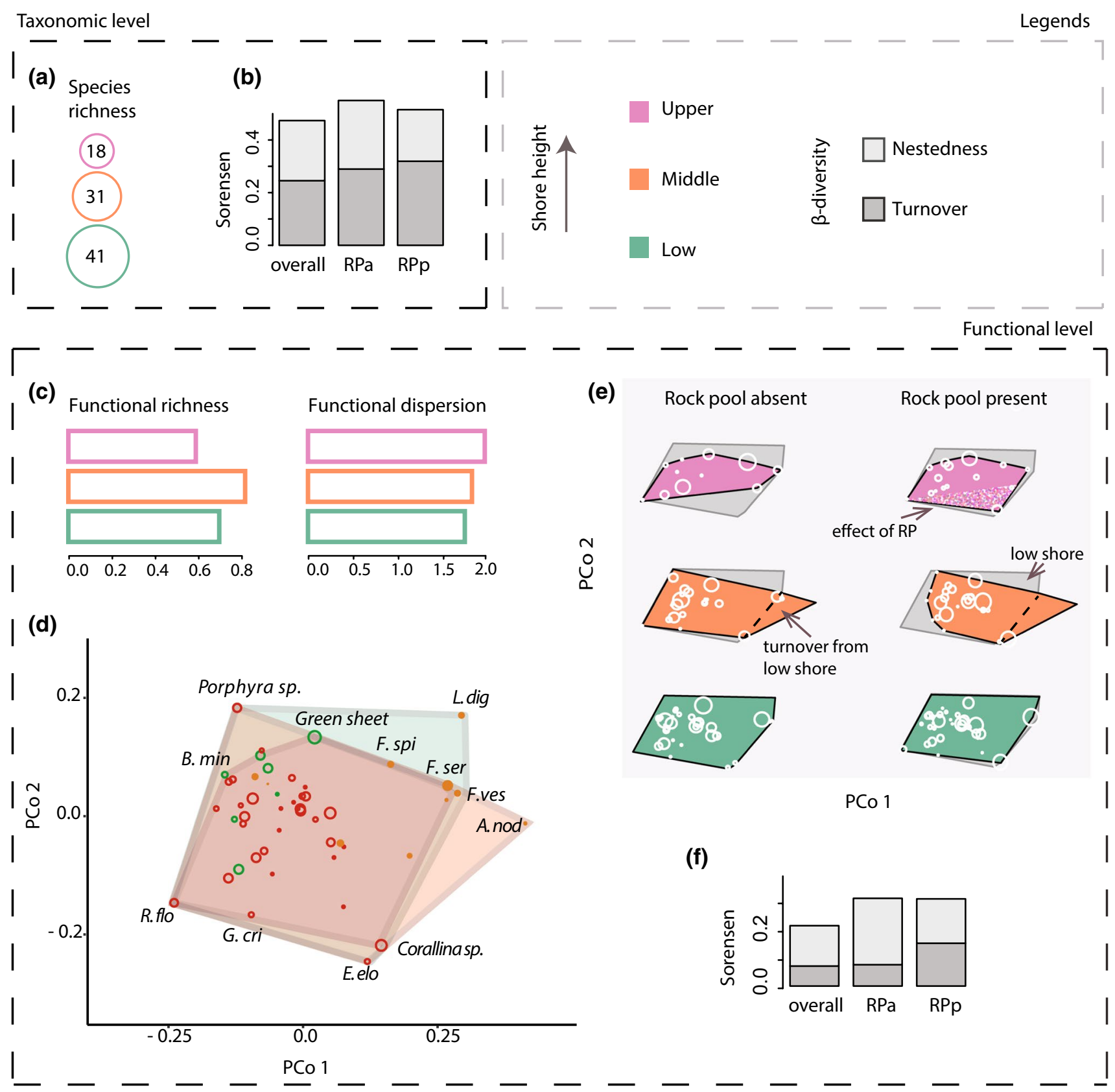

Fig. 3 Seaweed functional $\alpha$ - and $\beta$-diversity across intertidal zones (large scale), separated between the taxonomic and functional level. Panels a-b show species richness across zones and taxonomic $\beta$-diversity (divided into nestedness and turnover; for all communities and those with and without rock pools-RP). Panel $\mathbf{c}$ shows indices of functional richness (scaled to the potential maximum; details in Methods) and functional dispersion at each zone (all quadrats together). Panel $\mathbf{d}$ contains a representation of the two-dimensional trait space of the species pool ( $n=50$; PCoA biplot), indicating the zones with a coloured polygon. Species abbreviations are shown for those at the edges of the trait space at each height (complete names are given in Fig. 4). Panel $e$ shows the same functional space, but separately for each zone and habitat type. Circle sizes on $\mathbf{d}$ represent five frequency categories $(<10,<20,<30,<40$ and $<50)$, with circle colours referring to the algae group (brown algae: filled orange, green algae: hollow green, and red algae: hollow red); circle sizes on e are proportional to species local frequency. Nestedness is observed when a polygon is inside a larger one (represented in grey on panel e), while turnover is an expansion of a polygon (indicated in dashed line). Although we did not address $\beta$-diversity between habitats, we indicate the addition to the functional space with the presence of rock pools at the upper shore (pixelated pink). Barplots in panel $\mathbf{f}$ show the partition of functional $\beta$-diversity components, overall and for the two habitat categories 


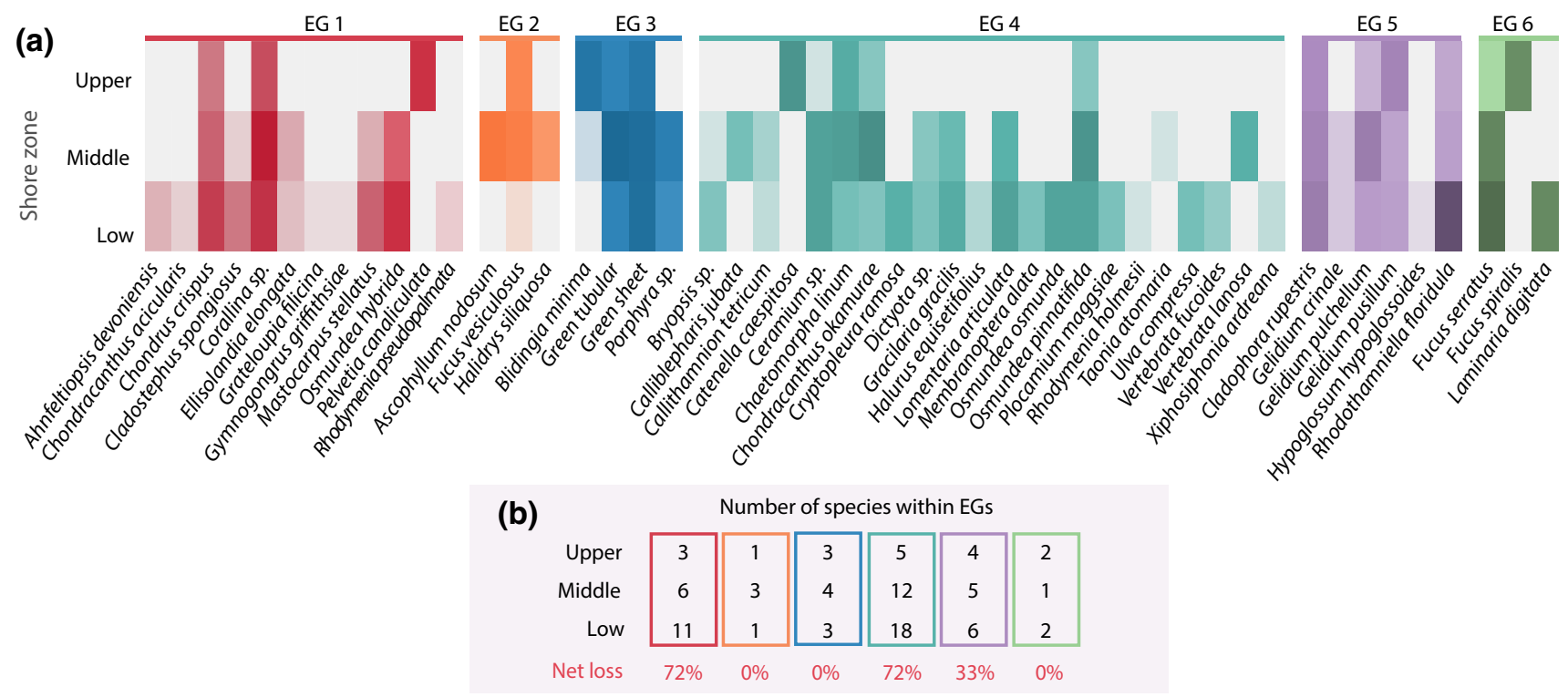

Fig. 4 Species' abundances and their assembly across the intertidal zones. a Species $(n=50)$ are sorted by emergent groups and abundance at each zone is log-transformed (values from 0 - white- to 6 - dark). b Number of species from each emergent group found at each zone, and percentage net loss from low to upper shore. Both panels are colour coded by emergent group (EG) the low shore with rock pools (Fig. 5e) and for functional dispersion in both low shore communities and middle shore with rock pools (Fig. 5f). The presence of rock pools had an additive effect on the SES of functional dispersion $(F=7.174, p<0.01)$ but not on the SES of functional richness $(F=0.175, p=0.7$; Table 2$)$. After obtaining these results, we ran the null models again, constraining the randomisations within zones, so that we could isolate the local effects from the whole-intertidal gradient effects. The over-dispersion was still observed, with patterns largely unchanged (Fig. S6, Appendix 6), indicating the role of small-scale (local) species interactions in driving functional over-dispersion. Overall, in low shore communities, species exhibited a greater total spread in trait space (functional richness) and abundant species were more distant to the centroid (functional dispersion) than expected, and this was further boosted in environments with rock pools. Contrary to our hypothesis there was no evidence that functional diversity was being limited due to environmental filtering at the upper shore (no under-dispersion).

\section{Discussion}

Our results show how the species and functional diversity of seaweed assemblages - as an example of marine habitat formers-change over the intertidal gradient. With the loss and turnover of species across the gradient, functional diversity declines in a metric- and scale-dependent fashion. This study demonstrates the use of modern functional diversity approaches in seaweed assemblages and illustrates how functional diversity can deepen our understanding of changes in marine habitat former communities under environmental stress.

Consistent with expectations, functional diversity decreased with increasing shore height, although metricand scale-dependently. Functional diversity often varies as a function of the facets and spatial scale considered, which may yield varying responses to environmental gradients (Smith et al. 2013). At the large scale, functional richness was the only metric to respond, illustrating its greater sensitivity to species-level changes and reflecting a decline in species with extreme functional traits in the upper shore. Further, the persistence of all emergent functional groups in the face of species loss can be attributed to the presence of redundant species within each group; although it is notable that certain emergent groups and upper shore assemblages have low redundancy and are thus vulnerable to future species loss. The finding that upper shore communities are nested within lower shore communities, rather than occupying a different part of trait space, illustrates a maintenance of the "core" functional structure, despite declines in functional richness. Together, the functional metrics reveal that, at large scales, the upper shore assemblages contain less functionally contrasting species, but retain a similar functional framework.

At the small scale, all metrics responded to the height gradient, although more strongly from middle to upper shore. For functional and emergent group richness, this pattern-changes only from middle to upper shore—can be 
Table 2 Summary of main effects from (generalised) linear models ((G)LMs) with diversity measures ( $\alpha$-diversity) as responses, and shore zone, presence of rock pool (RP), and their interaction as predictors

\begin{tabular}{|c|c|c|c|c|}
\hline GLMs & Deviance & Res. deviance & $F$ value & $p$ value \\
\hline \multicolumn{5}{|c|}{ Species richness } \\
\hline Zone & 96.333 & 105.873 & 40.618 & $<0.001$ \\
\hline $\mathrm{RP}$ & 13.117 & 92.756 & 11.061 & $<0.001$ \\
\hline Zone * RP & 0.006 & 92.749 & 0.002 & 0.99 \\
\hline \multicolumn{5}{|c|}{ Emergent group richness } \\
\hline Zone & 14.373 & 33.648 & 18.411 & $<0.001$ \\
\hline $\mathrm{RP}$ & 1.922 & 31.725 & 4.924 & $<0.05$ \\
\hline Zone * RP & 0.124 & 31.601 & 0.159 & 0.85 \\
\hline LMs & Sum of squares & Mean SSq & $F$ value & $p$ value \\
\hline \multicolumn{5}{|c|}{ Functional richness } \\
\hline Zone & 70,355 & 35,177 & 39.325 & $<0.001$ \\
\hline $\mathrm{RP}$ & 11,249 & 11,249 & 12.575 & $<0.001$ \\
\hline Zone * RP & 2327 & 1164 & 1.301 & 0.270 \\
\hline \multicolumn{5}{|c|}{ Functional dispersion } \\
\hline Zone & 94.670 & 47.340 & 13.955 & $<0.001$ \\
\hline $\mathrm{RP}$ & 38.390 & 38.390 & 11.317 & 0.001 \\
\hline Zone * RP & 2.470 & 1.240 & 0.365 & 0.69 \\
\hline \multicolumn{5}{|c|}{ SES Functional richness } \\
\hline Zone & 1.590 & 0.795 & 1.211 & 0.300 \\
\hline $\mathrm{RP}$ & 0.110 & 0.115 & 0.175 & 0.680 \\
\hline Zone * RP & 0.270 & 0.133 & 0.202 & 0.820 \\
\hline \multicolumn{5}{|c|}{ SES functional dispersion } \\
\hline Zone & 4.778 & 2.389 & 6.733 & 0.002 \\
\hline $\mathrm{RP}$ & 2.546 & 2.546 & 7.174 & 0.009 \\
\hline Zone * RP & 1.330 & 0.665 & 1.875 & 0.160 \\
\hline
\end{tabular}

For species and emergent group richness we used generalised linear models (family: quasipoisson); for functional richness and dispersion we used general linear models. Significant values are in bold

$R P a$ RP absent, $R P p$ RP present, $S E S$ standardised effect size

explained by their non-linear responses to species richness (Appendix 5). From middle to upper shore, where species richness reaches low levels at the small scale, declines in richness are occurring closer to the first—steep—section of the curve (few species). In contrast, from the lower to middle shore, declines in species richness take place further along the curves, so they cause smaller changes in functional and emergent group richness. However, the explanation for the similar response of functional dispersion is not as simple because, in theory, this metric is invariant to species richness (Laliberté and Legendre 2010). Besides a species richness mediated scale-dependency, the scale is also expected to determine the relative importance of environmental filtering and biotic interactions (Smith et al. 2013). Thus, species interactions may also help explain scale-dependent functional diversity changes across the intertidal gradient.

Indeed, functional over-dispersion points towards a key role of species interactions in the assembly of functionally diverse seaweeds. In particular, two biotic mechanisms may be largely responsible. First, interspecific competition, which has been widely documented in seaweeds (Hawkins and Hartnoll 1985; Edwards and Connell 2012), may result in the exclusion of functionally similar species from local communities (Macarthur and Levins 1967; Adler et al. 2013), promoting dissimilarity in traits of co-occurring species. The stronger over-dispersion in the more favourable lower shore further supports a key role of competition (Bertness and Callaway 1994) and is consistent with a study using categorical traits across seaweeds and invertebrates on Chilean rocky shores (Valdivia et al. 2017). Second, positive interactions such as facilitation and associational defences could also support species with contrasting traits (Teagle et al. 2017). The co-occurrence of functionally distinct species may be further promoted by small-scale environmental heterogeneity, as indicated by the enhancement of functional diversity metrics in the presence of rock pools. Overall, it seems that local-scale processes-likely involving species interactions-drove over-dispersion and effectively 
(a)

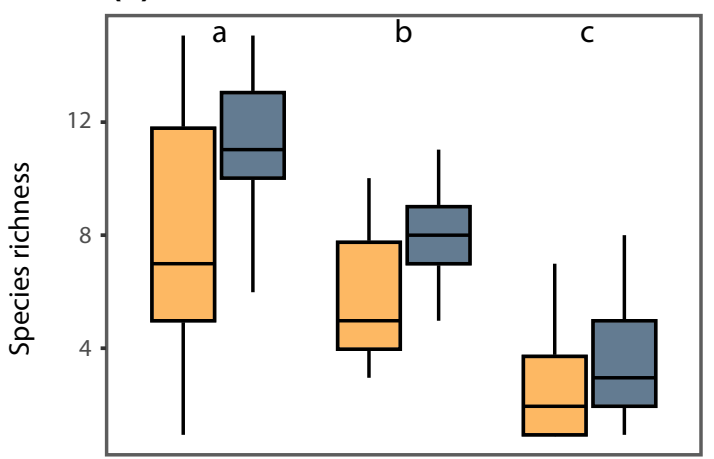

(c)

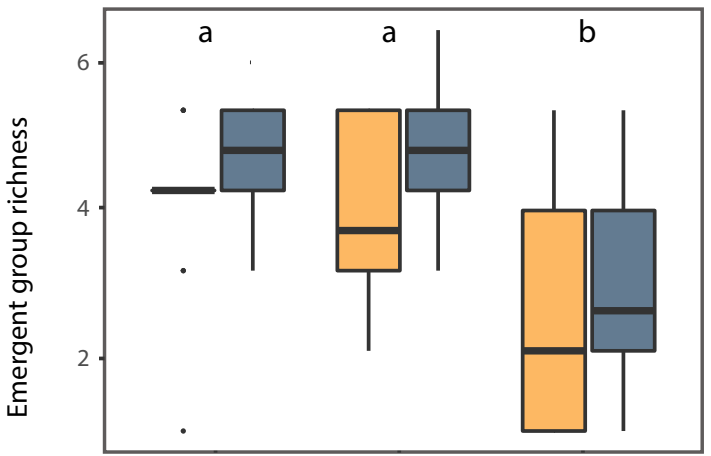

(e)

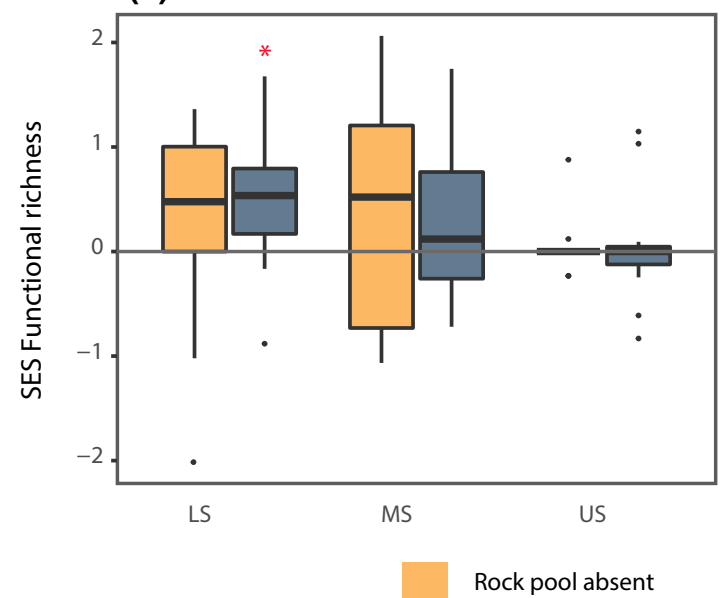

Fig. 5 Observed and SES values of species' and functional $\alpha$-diversity. Boxplots show values across-shore zones ( $L S$ low shore, $M S$ middle shore, and $U S$ upper shore), in quadrats with and without rock pools. Functional richness is scaled to the potential maximum (details in Methods). For observed values, different letters on top of boxes indicate zones are significantly different. For SES, values above

boosted functional diversity in the low shore and may help explain scale-dependent functional diversity responses to shore height. Our finding that over-dispersion patterns were maintained even when null models were restricted to species occurring within each respective zone further strengthens this conclusion. Nevertheless, although observational studies such as ours describe naturally-occurring patterns of (b)

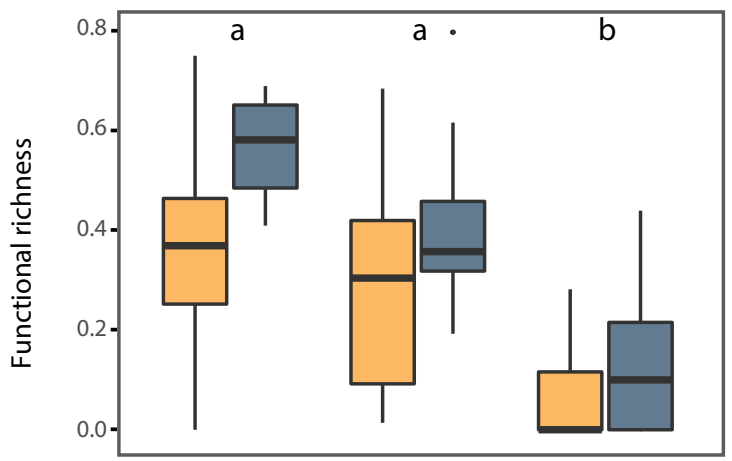

(d)

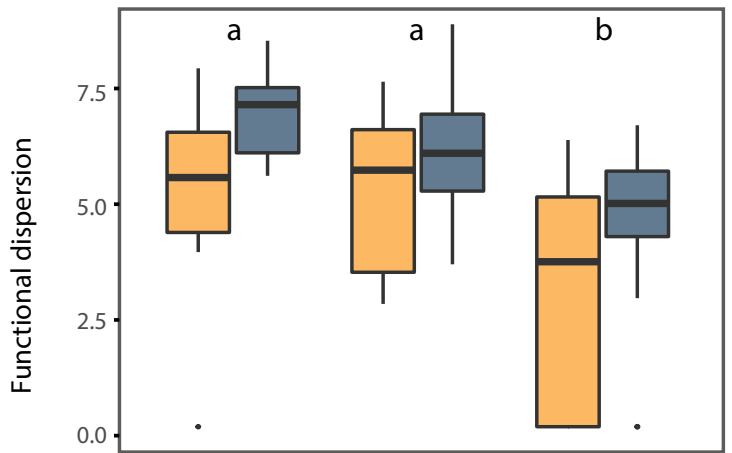

(f)

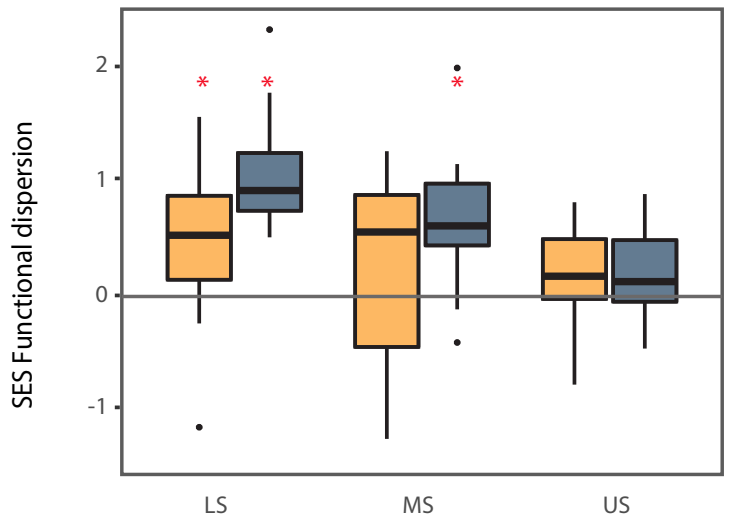

Rock pool present

or below the lines indicate deviance from null models, i.e. greater or lower than expected at random (asterisks indicate the significance of difference, obtained from one-sample $t$ test, or Wilcoxon rank test when data distribution was not normal). Constrained randomizations are given in Fig. S6; SES without the zone-defining Phaeophytes are given in Fig. S1

functional diversity and can show where functional diversity deviates from that expected under random assembly, only experiments can attempt to pin-down the relative and individual roles of the environment and species interactions in driving these patterns (Adler et al. 2013; Kraft et al. 2015).

Functional diversity approaches directly address the trait differences between species and, therefore, provide 
more insight than species-based measures into the potential consequences for ecosystem functioning (e.g. Le Bagousse-Pinguet et al. 2019). In our study, at the small scale, declines in functional richness and dispersion with increasing shore height reflect a reduction in both the total range of available traits and the distinctness of abundant species, potentially diminishing niche complementarity between co-occurring species (Cardinale et al. 2007; Stachowicz et al. 2008; Gamfeldt et al. 2015) and consequently ecosystem functioning (Griffin et al. 2009; Cadotte et al. 2011; Cadotte 2017). At the large scale, the smaller and nested functional space of upper shore communities, together with their lower redundancy, collectively indicate that these communities exhibit a reduced capacity to exploit environmental niches (Cardinale et al. 2000) and an impaired ability to withstand environmental changes (Loreau et al. 2003). Nevertheless, the persistence at this large scale of both functional dispersion and emergent group richness, as well as the maintenance of subset of core trait space, suggests resistance of some aspects of ecosystem functioning to the environmental gradient.

In conclusion, our results show that distinct aspects of seaweed functional diversity decline alongside species richness across the intertidal gradient. Yet patterns of change in functional diversity are scale-dependent: declines are stronger at the smaller scale, where both lower species richness and species interactions appear to be shaping functional diversity. These results bring a new perspective to the wellstudied pattern of seaweed intertidal zonation while pointing towards the role of local, biotic factors in shaping seaweed community assembly and resulting functional diversity. Our study also demonstrates the importance of considering different spatial scales in studies of changes in biodiversity across communities (Chase et al. 2018). Functional diversity studies in marine species have traditionally been limited by a lack of appropriate trait data. However, these are now emerging for corals (Madin et al. 2016), seagrasses (de los Santos et al. 2016) and seaweeds (Mauffrey et al. 2020b). Applying these newly available functional traits to assemblages of marine habitat formers across temporal-or as we did, spatial-gradients allows the characterisation of context-dependent functional structure (e.g., redundancy) as well as insights into potential sensitivity to environmental change and attendant species loss. Future studies could use similar approaches along gradients such as coastal development, ocean acidification (volcanic vents), and climate change-driven species loss or turnover (see Teixidó et al. 2018; Hall-Spencer et al. 2008; Wernberg et al. 2011; Pessarrodona et al. 2019).

Acknowledgements We thank the reviewers for the comments that helped improve the manuscript; we thank Josh Mutter, Olga Koppel and other Swansea University students for their valuable help in the field and lab work; we also thank Igor S. Pessi for his help throughout the study.

Author contribution statement LC and JNG conceived the study; LC and ARLM collected the data; LC and JNG analysed the data; all authors wrote the manuscript, led by LC.

Funding This study was funded by the Brazilian National Council for Scientific and Technological Development (CNPq-Science Without Borders Grant 202032/2015-9 to LC) and by a FP7 People Marie Curie Action Integration Career (FP7 MC CIG 61893 grant to J. Griffin). A. Mauffrey was supported by a Swansea University research scholarship.

\section{Compliance with ethical standards}

Conflict of interest The authors declare that they have no conflict of interest.

Open Access This article is licensed under a Creative Commons Attribution 4.0 International License, which permits use, sharing, adaptation, distribution and reproduction in any medium or format, as long as you give appropriate credit to the original author(s) and the source, provide a link to the Creative Commons licence, and indicate if changes were made. The images or other third party material in this article are included in the article's Creative Commons licence, unless indicated otherwise in a credit line to the material. If material is not included in the article's Creative Commons licence and your intended use is not permitted by statutory regulation or exceeds the permitted use, you will need to obtain permission directly from the copyright holder. To view a copy of this licence, visit http://creativecommons.org/licenses/by/4.0/.

\section{References}

Antão LH, Bates AE, Blowes SA et al (2020) Temperature-related biodiversity change across temperate marine and terrestrial systems. Nat Ecol Evol. https://doi.org/10.1038/s41559-020-1185-7

Adler PB, Fajardo A, Kleinhesselink AR, Kraft NJB (2013) Trait-based tests of coexistence mechanisms. Ecol Lett 16:1294-1306. https ://doi.org/10.1111/ele.12157

Araújo R, Sousa-Pinto I, Bárbara I, Quintino V (2006) Macroalgal communities of intertidal rock pools in the northwest coast of Portugal. Acta Oecologica 30:192-202. https://doi.org/10.1016/j. actao.2006.04.002

Ballantine WJ (1961) A biologically-defined exposure scale for the comparative description of rocky shores. Field Stud Counc $1: 1-19$

Baselga A (2010) Partitioning the turnover and nestedness components of beta diversity: partitioning beta diversity. Glob Ecol Biogeogr 19:134-143. https://doi.org/10.1111/j.1466-8238.2009.00490.x

Baselga A, Orme CDL (2012) betapart: an R package for the study of beta diversity: betapart package. Methods Ecol Evol 3:808-812. https://doi.org/10.1111/j.2041-210X.2012.00224.X

Begon M, Harper JL, Townsend CR (1996) Ecology: individuals, populations and communities. Blackwell, Oxford

Bertness MD, Callaway R (1994) Positive interactions in communities. Trends Ecol Evol 9:191-19310. https://doi.org/10.1016/01695347(94)90088-4

Blowes SA, Supp SR, Antão LH et al (2019) The geography of biodiversity change in marine and terrestrial assemblages. Science 366:339-345. https://doi.org/10.1126/science.aaw1620

Cadotte MW, Cavender-Bares J, Tilman D, Oakley TH (2009) Using phylogenetic, functional and trait diversity to understand patterns 
of plant community productivity. PLoS ONE 4:e5695. https:// doi.org/10.1371/journal.pone.0005695

Cadotte MW (2017) Functional traits explain ecosystem function through opposing mechanisms. Ecol Lett 20:989-996. https:// doi.org/10.1111/ele.12796

Cadotte MW, Carscadden K, Mirotchnick N (2011) Beyond species: functional diversity and the maintenance of ecological processes and services: functional diversity in ecology and conservation. J Appl Ecol 48:1079-1087. https://doi.org/10.111 1/j.1365-2664.2011.02048.x

Cadotte MW, Tucker CM (2017) Should environmental filtering be abandoned? Trends Ecol Evol 32:429-437. https://doi. org/10.1016/j.tree.2017.03.004

Cappelatti L, Mauffrey ARL, Griffin JN (2019) Applying continuous functional traits to large brown macroalgae: variation across tidal emersion and wave exposure gradients. Mar Biol 166:145. https ://doi.org/10.1007/s00227-019-3574-5

Cardinale BJ, Nelson K, Palmer MA (2000) Linking species diversity to the functioning of ecosystems: on the importance of environmental context. Oikos 91:175-183. https://doi.org/10.103 4/j.1600-0706.2000.910117.x

Cardinale BJ, Wright JP, Cadotte MW et al (2007) Impacts of plant diversity on biomass production increase through time because of species complementarity. Proc Natl Acad Sci 104:18123-18128. https://doi.org/10.1073/pnas.0709069104

Carpenter RC (1990) Competition among marine macroalgae: a physiological perspective. J Phycol 26(1):6-12. https://doi.org/10.111 1/j.0022-3646.1990.00006.x

Chapin FS, Bret-Harte MS, Hobbie SE, Zhong H (1996) Plant functional types as predictors of transient responses of arctic vegetation to global change. J Veg Sci 7:347-358. https://doi. org $/ 10.2307 / 3236278$

Chappuis E, Terradas M, Cefalì ME et al (2014) Vertical zonation is the main distribution pattern of littoral assemblages on rocky shores at a regional scale. Estuar Coast Shelf Sci 147:113-122. https:// doi.org/10.1016/j.ecss.2014.05.031

Chase JM, McGill BJ, McGlinn DJ et al (2018) Embracing scaledependence to achieve a deeper understanding of biodiversity and its change across communities. Ecol Lett 21:1737-1751. https://doi.org/10.1111/ele.13151

Cornelissen JHC, Lavorel S, Garnier E, Díaz S et al (2003) A handbook of protocols for standardised and easy measurement of plant functional traits worldwide. Aust J Bot 51:335-380

Cornwell WK, Schwilk DW, Ackerly DD (2006) A trait-based test for habitat filtering: convex hull volume. Ecology 87:1465-1471. https://doi.org/10.1890/0012-9658(2006)87[1465:ATTFH F]2.0.CO;2

Díaz S, Cabido M (2001) Vive la différence: plant functional diversity matters to ecosystem processes. Trends Ecol Evol 16:646-655. https://doi.org/10.1016/S0169-5347(01)02283-2

Díaz S, Settele J, Brondízio E et al (2020) Summary for policymakers of the global assessment report on biodiversity and ecosystem services of the Intergovernmental Science-Policy Platform on Biodiversity and Ecosystem Services. In: Global Assessment Report on Biodiversity and Ecosystem Services, IPBES.

Devictor V, Mouillot D, Meynard C et al (2010) Spatial mismatch and congruence between taxonomic, phylogenetic and functional diversity: the need for integrative conservation strategies in a changing world: spatial mismatch between diversity facets. Ecol Lett 13:1030-1040. https://doi.org/10.111 1/j.1461-0248.2010.01493.x

Dring MJ, Brown FA (1982) Photosynthesis of intertidal brown algae during and after periods of emersion: a renewed search for physiological causes of zonation. Mar Ecol Prog Ser 8:301-308. https ://doi.org/10.3354/meps008301
Dromgoole FI (1981) Form and function of the pneumatocysts of marine algae. I. Variations in the pressure and composition of internal gases. Bot Mar 24:257-266. https://doi.org/10.1515/ botm.1981.24.5.257

Edwards MS, Connell SD (2012) Competition, a major factor structuring seaweed communities. In: Wiencke C, Bischof K (eds) Seaweed biology. Springer Berlin Heidelberg, Berlin, Heidelberg, pp 135-156

Elger A, Willby NJ (2003) Leaf dry matter content as an integrative expression of plant palatability: the case of freshwater macrophytes. Funct Ecol 17:58-65

Firth LB, Schofield M, White FJ et al (2014) Biodiversity in intertidal rock pools: Informing engineering criteria for artificial habitat enhancement in the built environment. Mar Environ Res 102:122-130. https://doi.org/10.1016/j.marenvres.2014.03.016

Fong CR, Fong P (2014) Why species matter: an experimental assessment of assumptions and predictive ability of two functional-group models. Ecology 95:2055-2061. https://doi. org/10.1890/13-1557.1

Gamfeldt L, Lefcheck JS, Byrnes JEK et al (2015) Marine biodiversity and ecosystem functioning: what's known and what's next? Oikos 124:252-265. https://doi.org/10.1111/oik.01549

Garnier E, Cortez J, Billès G et al (2004) Plant functional markers capture ecosystem properties during secondary succession. Ecology 85:2630-2637. https://doi.org/10.1890/03-0799

Gómez I, Huovinen P (2011) Morpho-functional patterns and zonation of South Chilean seaweeds: the importance of photosynthetic and bio-optical traits. Mar Ecol Prog Ser 422:77-91. https://doi. org/10.3354/meps08937

Gotelli NJ, Chao A (2013) Measuring and estimating species richness, species diversity, and biotic similarity from sampling data. In: Encyclopedia of biodiversity. Elsevier, Amsterdam, pp 195-211

Griffin JN, Méndez V, Johnson AF, Jenkins SR, Foggo A (2009) Functional diversity predicts overyielding effect of species combination on primary productivity. Oikos 118:37-44. https://doi.org/ 10.1111/j.1600-0706.2008.16960.x

Hall-Spencer JM, Rodolfo-Metalpa R, Martin S et al (2008) Volcanic carbon dioxide vents show ecosystem effects of ocean acidification. Nature 454:96-99. https://doi.org/10.1038/nature07051

Harley CDG, Anderson KM, Demes KW et al (2012) Effects of climate change on global seaweed communities. J Phycol 48:1064-1078. https://doi.org/10.1111/j.1529-8817.2012.01224.x

Hawkins S, Hartnoll R (1985) Factors determining the upper limits of intertidal canopy-forming algae. Mar Ecol Prog Ser 20:265-271. https://doi.org/10.3354/meps020265

Hay ME (1981) The functional morphology of turf forming seaweeds: persistence in stressful marine habitats. Ecology 62:739-750

Hervé M (2020) RVAideMemoire: testing and plotting procedures for biostatistics. R package version 0.9-74. https://CRAN.R-proje ct.org/package=RVAideMemoire. Accessed Feb 2020

Ingólfsson A (2005) Community structure and zonation patterns of rocky shores at high latitudes: an interocean comparison: rocky shore communities at high latitudes. J Biogeogr 32:169-182. https://doi.org/10.1111/j.1365-2699.2004.01150.x

Isbell F, Gonzalez A, Loreau M et al (2017) Linking the influence and dependence of people on biodiversity across scales. Nature 546:65-72. https://doi.org/10.1038/nature22899

Johnson MP, Hawkins SJ, Hartnoll RG, Norton TA (1998) The establishment of fucoid zonation on algal-dominated rocky shores: hypotheses derived from a simulation model. Funct Ecol 12:259269. https://doi.org/10.1046/j.1365-2435.1998.00185.x

Kraft NJB, Adler PB, Godoy O et al (2015) Community assembly, coexistence and the environmental filtering metaphor. Funct Ecol 29:592-599. https://doi.org/10.1111/1365-2435.12345 
Kuebbing SE, Maynard DS, Bradford MA (2018) Linking functional diversity and ecosystem processes: a framework for using functional diversity metrics to predict the ecosystem impact of functionally unique species. J Ecol 106:687-698. https://doi. org/10.1111/1365-2745.12835

Laliberté E, Legendre P (2010) A distance-based framework for measuring functional diversity from multiple traits. Ecology 91:299305. https://doi.org/10.1890/08-2244.1

Le Bagousse-Pinguet Y, Soliveres S, Gross N et al (2019) Phylogenetic, functional, and taxonomic richness have both positive and negative effects on ecosystem multifunctionality. Proc Natl Acad Sci. https://doi.org/10.1073/pnas.1815727116

Lefcheck JS, Duffy JE (2015) Multitrophic functional diversity predicts ecosystem functioning in experimental assemblages of estuarine consumers. Ecology 96:2973-2983. https://doi. org/10.1890/14-1977.1

Legendre P (2014) Interpreting the replacement and richness difference components of beta diversity: replacement and richness difference components. Glob Ecol Biogeogr 23:1324-1334. https:// doi.org/10.1111/geb.12207

Littler MM, Littler DS (1980) The evolution of thallus form and survival strategies in benthic marine macroalgae: field and laboratory tests of a functional form model. Am Nat 116:25-44. https ://doi.org/10.1086/283610

Loreau M, Mouquet N, Gonzalez A (2003) Biodiversity as spatial insurance in heterogeneous landscapes. Proc Natl Acad Sci 100:12765-12770. https://doi.org/10.1073/pnas.2235465100

Lubchenco J (1980) Algal zonation in the New England rocky intertidal community: an experimental analysis. Ecology 61:333-344. https://doi.org/10.2307/1935192

Macarthur R, Levins R (1967) The limiting similarity, convergence, and divergence of coexisting species. Am Nat 101:377-385. https ://doi.org/10.1086/282505

Madin JS, Hoogenboom MO, Connolly SR, Darling ES, Falster DS, Huang D, Keith SA, Mizerek T, Pandolfi JM, Putnam HM, Baird AH (2016) A trait-based approach to advance coral reef science. Trends Ecol Evol 31:419-428. https://doi.org/10.1016/j. tree.2016.02.012

Maechler M, Rousseeuw P, Struyf A, Hubert M, Hornik K (2019) Cluster: cluster analysis basics and extensions. $\mathrm{R}$ package version 2.1.0. https://cran.r-project.org/web/packages/cluster/. Accessed Feb 2020

Mason NWH, Mouillot D, Lee WG, Wilson JB (2005) Functional richness, functional evenness and functional divergence: the primary components of functional diversity. Oikos 111:112-118. https:// doi.org/10.1111/j.0030-1299.2005.13886.x

Mauffrey ARL, Cappelatti L, Griffin JN (2020a) Seaweed functional diversity revisited: confronting traditional groups with quantitative traits. J Ecol 00:1-16. https://doi. org/10.1111/1365-2745.1346

Mauffrey ARL, Cappelatti L, Griffin JN (2020b) Data from: functional diversity of seaweeds revisited: confronting traditional groups with quantitative traits. Dryad Dataset. https://doi.org/10.5061/ dryad.nvx0k6dpn

Mcgill B, Enquist B, Weiher E, Westoby M (2006) Rebuilding community ecology from functional traits. Trends Ecol Evol 21:178185. https://doi.org/10.1016/j.tree.2006.02.002

Micheli F, Halpern BS (2005) Low functional redundancy in coastal marine assemblages. Ecol Lett 8:391-400. https://doi.org/10.11 11/j.1461-0248.2005.00731.x

Mokany K, Ash J, Roxburgh S (2008) Functional identity is more important than diversity in influencing ecosystem processes in a temperate native grassland: determinants of ecosystem processes. J Ecol 96:884-893. https://doi.org/10.111 $1 /$ j.1365-2745.2008.01395.x
Mouillot D, Graham NAJ, Villéger S et al (2013) A functional approach reveals community responses to disturbances. Trends Ecol Evol 28:167-177. https://doi.org/10.1016/j.tree.2012.10.004

Mouillot D, Villeger S, Parravicini V et al (2014) Functional overredundancy and high functional vulnerability in global fish faunas on tropical reefs. Proc Natl Acad Sci 111:13757-13762. https ://doi.org/10.1073/pnas.1317625111

Muguerza N, Bustamante M, Díez I et al (2020) Long-term surveys reveal abrupt canopy loss with immediate changes in diversity and functional traits. Mar Biol 167:61. https://doi.org/10.1007/ s00227-020-3675-1

Pessarrodona A, Foggo A, Smale DA (2019) Can ecosystem functioning be maintained despite climate-driven shifts in species composition? Insights from novel marine forests. J Ecol 107:91-104. https://doi.org/10.1111/1365-2745.13053

De los Santos CB, Onoda Y, Vergara JJ, Pérez-Lloréns JL et al (2016) A comprehensive analysis of mechanical and morphological traits in temperate and tropical seagrass species. Mar Ecol Prog Ser 551:81-94. https://doi.org/10.3354/meps11717

Reich PB, Ellsworth DS, Walters MB, Vose JM, Gresham C, Volin JC, Bowman WD (1999) Generality of leaf trait relationships: a test across six biomes. Ecology 80:1955-1969

Reynolds AP, Richards G, de la Iglesia B, Rayward-Smith VJ (2006) Clustering rules: a comparison of partitioning and hierarchical clustering algorithms. J Math Model Algorithm 5(4):475-504. https://doi.org/10.1007/s10852-005-9022-1

Roderick ML, Berry SL, Noble IR (2000) A framework for understanding the relationship between environment and vegetation based on the surface area to volume ratio of leaves. Funct Ecol $14: 423-437$

Rodriguez S, Martín AP, Sousa-Pinto I, Arenas F (2016) Biodiversity effects on macroalgal productivity: exploring the roles of richness, evenness and species traits. Mar Ecol Prog Ser 562:79-91. https://doi.org/10.3354/meps11948

Rosenfeld JS (2002) Functional redundancy in ecology and conservation. Oikos 98:156-162

Schellenberger Costa D, Gerschlauer F, Pabst H et al (2017) Community-weighted means and functional dispersion of plant functional traits along environmental gradients on Mount Kilimanjaro. J Veg Sci 28:684-695. https://doi.org/10.1111/jvs.12542

Schonbeck MW, Norton TA (1979) Drought-hardening in the uppershore seaweeds fucus spiralis and pelvetia canaliculata. J Ecol 67:687. https://doi.org/10.2307/2259120

Scrosati R, Heaven C (2007) Spatial trends in community richness, diversity, and evenness across rocky intertidal environmental stress gradients in eastern Canada. Mar Ecol Prog Ser 342:114. https://doi.org/10.3354/meps342001

Scrosati RA, Knox AS, Valdivia N, Molis M (2011) Species richness and diversity across rocky intertidal elevation gradients in Helgoland: testing predictions from an environmental stress model. Helgol Mar Res 65:91. https://doi.org/10.1007/s1015 2-010-0205-4

Seger GDS, Cappelatti L, Gonçalves LO et al (2017) Phylogenetic and functional structure of climbing plant assemblages in woody patches advancing over Campos grassland. J Veg Sci 28:1187-1197. https://doi.org/10.1111/jvs. 12568

Singer FD (2016) Ecology in action. Cambridge University Press, Cambridge, p 719

Smale DA, Burrows MT, Moore P et al (2013) Threats and knowledge gaps for ecosystem services provided by kelp forests: a northeast Atlantic perspective. Ecol Evol 3:4016-4038. https ://doi.org/10.1002/ece3.774

Smith AB, Sandel B, Kraft NJB, Carey S (2013) Characterizing scale-dependent community assembly using the functionaldiversity-area relationship. Ecology 94:2392-2402. https:// doi.org/10.1890/12-2109.1 
Sol D, Trisos C, Múrria C et al (2020) The worldwide impact of urbanisation on avian functional diversity. Ecol Lett 23:962972. https://doi.org/10.1111/ele.13495

Stachowicz JJ, Bruno JF, Duffy JE (2007) Understanding the effects of marine biodiversity on communities and ecosystems. Annu Rev Ecol Evol Syst 38:739-766. https://doi.org/10.1146/annur ev.ecolsys.38.091206.095659

Stachowicz JJ, Graham M, Bracken MES, Szoboszlai AI (2008) Diversity enhances cover and stability of seaweed assemblages: the role of heterogeneity and time. Ecology 89(11):3008-3019. https://doi.org/10.1890/07-1873.1

Starko S, Claman BZ, Martone PT (2015) Biomechanical consequences of branching in flexible wave-swept macroalgae. New Phytol 206(1):133-140. https://doi.org/10.1111/nph.13182

Steneck RS, Dethier MN (1994) A functional group approach to the structure of algal-dominated communities. Oikos 69:476. https ://doi.org/10.2307/3545860

Stephenson TA, Stephenson A (1949) The universal features of zonation between tidemarks on rocky shores. J Ecol 38:289-305

Stevens RD, Gavilanez MM (2015) Dimensionality of community structure: phylogenetic, morphological and functional perspectives along biodiversity and environmental gradients. Ecography 38:861-875. https://doi.org/10.1111/ecog.00847

Stewart HL, Carpenter RC (2003) The effects of morphology and water flow on photosynthesis of marine macroalgae. Ecology 84(11):2999-3012

Swenson N (2014) Functional and Phylogenetic Ecology in R. Springer, New York, p 212

Tait LW, Hawes I, Schiel DR (2014) Shining light on benthic macroalgae: mechanisms of complementarity in layered macroalgal assemblages. PLoS ONE 9:e114146. https://doi.org/10.1371/ journal.pone.0114146

Taylor PR, Hay ME (1984) Functional morphology of intertidal seaweeds: adaptive significance of aggregate vs. solitary forms. Mar Ecol Prog Ser 18:295-302

Teagle H, Hawkins SJ, Moore PJ, Smale DA (2017) The role of kelp species as biogenic habitat formers in coastal marine ecosystems. J Exp Mar Biol Ecol 492:81-98. https://doi.org/10.1016/j.jembe .2017.01.017
Teixidó N, Gambi MC, Parravacini V et al (2018) Functional biodiversity loss along natural $\mathrm{CO}_{2}$ gradients. Nat Commun 9:5149. https ://doi.org/10.1038/s41467-018-07592-1

Tilman D (2001) Functional diversity. Encyclopaedia of biodiversity. Academic Press, San Diego, pp 109-120

Thomsen MS, Wernberg T, Altieri A et al (2010) Habitat cascades: the conceptual context and global relevance of facilitation cascades via habitat formation and modification. Integr Comp Biol 50:158-175. https://doi.org/10.1093/icb/icq042

Underwood AJ, Jernakoff P (1984) The effects of tidal height, waveexposure, seasonality and rock-pools on grazing and the distribution of intertidal macroalgae in New South Wales. J Exp Mar Biol Ecol 75:71-96. https://doi.org/10.1016/0022-0981(84)90024-8

Valdivia N, Segovia-Rivera V, Fica E et al (2017) Context-dependent functional dispersion across similar ranges of trait space covered by intertidal rocky shore communities. Ecol Evol 7:1882-1891. https://doi.org/10.1002/ece3.2762

Vergés A, McCosker E, Mayer-Pinto M et al (2019) Tropicalisation of temperate reefs: implications for ecosystem functions and management actions. Funct Ecol 1365-2435:13310. https://doi. org/10.1111/1365-2435.13310

Villéger S, Mason NWH, Mouillot D (2008) New multidimensional functional diversity indices for a multifaceted framework in functional ecology. Ecology 89:2290-2301. https://doi. org/10.1890/07-1206.1

Violle C, Navas ML, Vile D et al (2007) Let the concept of trait be functional! Oikos 116:882-892

Wernberg T, Russell BD, Thomsen MS et al (2011) Seaweed communities in retreat from ocean warming. Curr Biol 21:1828-1832. https://doi.org/10.1016/j.cub.2011.09.028

Weykam G, Gómez I, Wiencke C et al (1996) Photosynthetic characteristics and C: $\mathrm{N}$ ratios of macroalgae from King George Island (Antarctica). J Exp Mar Biol Ecol 204:1-22

Zhang JT, Lihong F, Min L (2012) Functional diversity in plant communities: theory and analysis methods. Afr J Biotechnol 11:1014-1022. https://doi.org/10.5897/AJB11.3122 